\title{
Seeking Information: A Survey of Rural Spinal Patients' Internet Use and Pain Catastrophizing
}

\author{
Kelly A. Thomas ${ }^{1}$ Cara Sedney ${ }^{2}$ Richard Gross ${ }^{3}$ \\ 1Department of Counseling, Rehabilitation Counseling, and \\ Counseling Psychology, West Virginia University, Morgantown, \\ West Virginia, United States \\ 2West Virginia University Rockefeller Neuroscience Institute, \\ Morgantown, West Virginia, United States \\ ${ }^{3}$ WVU Center for Integrative Pain Management, West Virginia \\ University, Morgantown, West Virginia, United States
}

\begin{abstract}
Address for correspondence Cara Sedney, MD, Neurosurgery
Clinic, West Virginia University, 1 Medical Center Drive, Morgantown, WV 26505, United States (e-mail: csedney@hsc.wvu.edu).
\end{abstract}

J Neurosci Rural Pract 2021;12:308-315.

\section{Introduction}

The Internet is a widespread tool utilized in $90 \%$ of US households. ${ }^{1}$ In addition, $4.5 \%$ of total Internet searches are for health-related information, with an estimated 6.75 million health-related searches occurring every day. ${ }^{2}$ Thirty-nine percent of individuals who utilize the Internet for health-related concerns specifically searched for information on pain they were experiencing. ${ }^{3}$ In a previous study on the prevalence of Internet use for spinal surgery patients in a European sample, $23 \%$ of their participants used the published online March 24, 2021
DOI https://doi.org/

$10.1055 / \mathrm{s}-0041-1722837$ ISSN 0976-3147.
(C) 2021. Association for Helping Neurosurgical Sick People.

This is an open access article published by Thieme under the terms of the Creative Commons Attribution-NonDerivative-NonCommercial-License, permitting copying and reproduction so long as the original work is given appropriate credit. Contents may not be used for commercial purposes, or adapted, remixed, transformed or built upon. (https://creativecommons.org/licenses/by-nc-nd/4.0/).

Thieme Medical and Scientific Publishers Pvt. Ltd. A-12, 2nd Floor, Sector 2, Noida-201301 UP, India 
Internet to search their spinal condition. ${ }^{4}$ With a majority of the population being Internet users, medical professionals are beginning to question whether seeking medical information through the Internet for health-related concerns is a positive or negative tool in their practice. ${ }^{5-7}$ The term cyberchondria was created to describe fear or increased attention to serious medical diagnoses due to Internet search results. ${ }^{8}$ From the perspective of the patient, the Internet provides the opportunity to increase competence, change maladaptive health behaviors, and increases the probability of engaging with health-professionals when making health-decisions. ${ }^{9}$

Psychological variables are critical to consider due to how pain-related fears may impact surgical recovery and increase disability. ${ }^{10-12}$ More specifically, the variable pain catastrophizing is defined as a negative orientation toward possible future experiences that may contribute to maladaptive coping of ones' pain experience. ${ }^{13}$ There have been few studies that specifically note the association between pain catastrophizing and Internet use. One study utilizing a small adolescent south-west England sample found that adolescents who did use the Internet to seek information scored higher on the child version of the pain catastrophizing scale (PCS). ${ }^{14}$ Additionally, a study on the role pain catastrophizing plays in cyberchondria found that pain catastrophizing contributed to the variance within four domains including compulsion, distress, excessiveness, and reassurance. ${ }^{15}$

The concern expressed by medical professionals' experience regarding patients' cyberchondria or health anxiety due to the Internet is a valid consideration in how it may disrupt treatment planning. The current study investigates the way rural patients in the Appalachian region utilize the Internet for information on their spinal diagnosis and/or receive support online. Additionally, this study considers the relationship between Internet use and pain catastrophizing. It is hypothesized that spinal patients will use the Internet more often for information on their conditions over using this tool for social support. It is also hypothesized that participants who use the Internet for online social support will have elevated levels of pain catastrophizing. The overall aim of the study is to provide descriptive information for clinicians, so they have the opportunity to offer their patients with proper Internet resources, as well as provide supplementary information on Internet use and pain catastrophizing.

\section{Materials and Methods}

\section{Design}

This study utilizes a quantitative-descriptive, survey-based, correlational, cross-sectional design. ${ }^{16}$ Data sources include patient demographics, the PCS, and an Internet use and spine patient (IUSP) questionnaire, which was developed by the investigators of this current study. Descriptive statistics were computed to provide a snapshot of rural patients' Internet use regarding their spinal diagnosis. Additionally, a bivariate correlational analysis was conducted to determine the relationship between Internet use and pain catastrophizing.

\section{Sample}

A G*Power 3.1. software was employed to determine the number of participants needed to achieve statistical power. Faul et $\mathrm{al}^{17}$ offer recommendations on calculations that are appropriate for determining an effect size for correlational analyses. Once applying these recommendations, a total minimum sample size was determined to be 84 individuals. This number was calculated based on a medium effect size of $|\rho|=0.3$, a Power (1- $\beta$ err prob) of 0.80 , and an $\alpha(\alpha)$ of $0.05 .{ }^{17}$ Therefore, a total of 143 individuals completed the surveys to achieve significant statistical power. Participants who were over the age of 18 and were presenting for intake to the neurosurgery clinic at a mid-Atlantic medical center were included.

\section{Instruments}

A 12-item IUSP questionnaire was developed by one of the authors of this project with support from other members of the research group and clinic. These questions were established through preliminary interviews conducted with patients at a mid-Atlantic neurosurgery clinic. The first and second items are demographics regarding the participants age and what methods are used by the patient when conducting Internet searches (i.e., tablet, phone, computer, "other"). Examples of questions on the IUSP include "How often have you done an Internet search for your spinal diagnosis" and "Have you utilized online support groups for your spinal diagnosis" (-Fig. 1). The questions were aimed at learning whether spinal patients were utilizing the Internet for information (questions 1 and 7) and/or support (questions 3 and 5). Additionally, questions two, four, and six were aimed at learning if gaining information or support from the Internet was helpful to the patient. Questions on the IUSP were rated on a 5 -point Likert scale (i.e., $1=$ never to $5=a$ great deal, $1=$ not at all to $5=$ a great deal $)$.

The PCS was used as an outcome measure in this study to measure the role of catastrophizing and its relationship to Internet use. The PCS has three subscales: rumination, magnification, and helplessness. ${ }^{18}$ The total score of the PCS can be utilized to represent total pain catastrophizing. Participants respond using five frequency ratings: 0 (not at all), 1 (to a slight degree), 2 (to a moderate degree), 3 (to a great degree), and 4 (all the time). The PCS has evidence of good internal consistency and reliability for all subscales. ${ }^{18}$

\section{Data Collection}

Participants include spinal patients presenting at a neurosurgery clinic for intake at a mid-Atlantic medical facility. All participants consented prior to the administration of the IUSP and the PCS. Demographic data included the patients' age. All procedures of this study were in accordance with the WVU Institutional Review Board.

\section{Data Analysis}

Means and standard deviations of the age of our participants were calculated separately for Internet and non-Internet users to provide our first descriptive look of the demographic. A frequency analysis and bivariate correlation 


\section{Internet Use and Spine Patients}

(Please circle your answer or write in the space provided)

What is your age?

What ways do you access the internet? Please circle all that apply. PhoneTabletComputer Other

\section{How often have you done an internet search for your spinal diagnosis?}

2

3

4

5

Never

Occasionally

A great deal

\section{If yes, how helpful did you find the internet search to be?}

A great deal

\section{Have you utilized online support groups for your spinal diagnosis?}

1

Never
2

3

Occasionally
4 5

A great deal

Fig. 1 Internet use and spine patients questionnaire.

analysis were conducted on Internet users only. NonInternet users were excluded for the additional analyses to lower the opportunity for negative skewing of the data. SPSS version 24 (IBM Corp., Armonk, New York, United States) was used to calculate frequencies and correlations. The scores from the PCS were calculated to reflect the three subscales: rumination (items 8-11), magnification (items 6, 7, and 13), and helplessness (items $1-5$ and 12), as well as a total catastrophizing score. Mean catastrophizing scores were paralleled to a raw score-to-percentile chart developed by Sullivan ${ }^{18}$ to compare our sample population to a chronic pain normative sample. 


\section{If yes, how helpful did you find online support groups to be?}

1

3

4

5

Not at allSomewhat

A great deal

5. How often have you used social media (Twitter, Instagram, Facebook, etc.) to discuss your spinal condition?

1

Never
2

3

Occasionally
4

5

A great deal

6. If yes, how helpful did you find social media to be?

1

2

3

4

5

Not at allSomewhat

A great deal

7. How often did you use physician reviews for your spinal diagnosis?

1

2

3

4

5

Never

Occasionally

A great deal

8. If yes, how helpful did you find these to be?
1
2
3
4
5

Not at allSomewhat

A great deal

Fig. 1 (continued)

It is first hypothesized that spinal patient's will be more likely to use the Internet for information reasons, rather than for support. This was examined using a frequency distribution. For the second hypothesis, it is believed that individuals who report higher use of the Internet for support versus information will show elevated scores on the PCS. This was examined utilizing a correlation bivariate normal model.

\section{Results}

Sample Demographics

Of the 143 individuals who completed the questionnaires, 137 reported that they utilize the Internet, and 6 reported they did not use the Internet at all. For the participants who do not use the Internet $(n=6)$, their ages ranged from 61 to 


\section{How much did what you found online caused you to change what you}

\section{thought or how you felt about your diagnosis?}

1

Never
2

3

Occasionally
4

5

A great deal

If you have any additional comments, please write them on the back of this page.

Fig. 1 (countinued)

$82(\mathrm{M}=73$, standard deviation $[S D]=8.426)$. For the participants who do use the Internet $(n=137)$, their ages ranged from 20 to $79(\mathrm{M}=52.17, \mathrm{SD}=13.100)$.

Sullivan provides a raw score to associated percentiles table for each PCS subscale. ${ }^{18}$ This was normed through a sample of 851 men and women with chronic pain. The pain catastrophizing means from our rural spine patients were compared with Sullivan's pain catastrophizing table to provide descriptive information on how our sample compares to a normed demographic. Rural-Appalachian spinal patients who utilize the Internet in this study report rumination at the 60th percentile rank relative to a normed chronic pain sample $(M=9.37, S D=4.76)$. For the subscale magnification, our sample scored at the 77 th percentile rank relative to Sullivan's chronic pain sample group $(\mathrm{M}=5.52, \mathrm{SD}=3.30) .{ }^{18}$ The subscale helplessness was recorded at the 66th percentile $\operatorname{rank}(M=11.43$, $\mathrm{SD}=6.41)$. Finally, the total score of the PCS in our sample 
population of rural-Appalachia scored at the 65th percentile rank as compared with a normed chronic pain sample $(\mathrm{M}=26.31, \mathrm{SD}=13.30)$.

\section{$\mathbf{H}_{1}$ : Frequencies of Internet Use in the Rural Spine Patients} Descriptive information on Internet frequencies was calculated on the Internet use population only. A summary of participant frequencies $(n, \%)$ is presented in - Table 1. Question one states, "How often have you done an Internet search for your spinal diagnosis?" Results indicate that our sample of spinal patients have utilized the Internet to research their spinal condition at least once and find the Internet to be somewhat helpful for research purposes. Question three states: "Have you utilized online support groups for your spinal diagnosis?." Most of our rural spinal participants reported that they have never used the Internet for support. Of the individuals who did utilize online support groups, most reported it was unhelpful. Question five states: "How often have you used social media (Twitter, Instagram, Facebook, etc.) to discuss your spinal condition?" Similar to question three, most spinal patients reported that they had not utilized social media for support, and for those who did utilize social media, almost all participants stated that it was unhelpful.

Question seven states: "How often did you use physician reviews for your spinal diagnosis?." Slightly more than half describe never utilizing physician reviews. Of the individuals who did utilize the Internet for physician reviews, most reported it was not helpful. Finally, the last question (Q9) states: "How much did what you found online cause you to change what you thought or how you felt about your diagnosis?." Most of the participants stated that their Internet searches did not change how they thought or felt about their diagnosis.

\section{$\mathbf{H}_{2:}$ Internet Use and Pain Catastrophizing}

It was hypothesized that spinal patients who report higher use of the Internet for support will show elevated scores on the PCS. The only significant correlation between a single IUSP item on Internet use and pain catastrophizing was between question five (i.e., How often have you used social media (Twitter, Instagram, Facebook, etc.) to discuss your spinal condition?) and PCS-subscale magnification $(p=0.016)$ (-Table 2). Additionally, the subscales of the IUSP were computed by summing items one and seven for the subscale Information, and items three and five for the subscale support. There was a one significant relationship between the IUSP subscale, Information, and the PCS-subscale Helplessness $(p=0.020)$. Regarding the IUSP subscale, support, there were three positively correlated PCS subscales: magnification $(p=0.020)$, helplessness $(p=0.033)$, and PCS total $(p=0.044)$.

\section{Discussion}

The aim of this study was to provide clinicians with a descriptive view of patients' Internet use to find information and/or support on their spinal condition, as well as how their

Table 1 Summary of frequencies (number of patients, valid percent) for questions on the Internet use and spine patients questionnaire

\begin{tabular}{|c|c|c|c|c|c|}
\hline & $\begin{array}{l}\text { Q1 } \\
N(\text { valid })=132, \\
N(\text { missing })=5\end{array}$ & $\begin{array}{l}\text { Q3 } \\
N(\text { valid })=130 \\
N(\text { missing })=7\end{array}$ & $\begin{array}{l}\text { Q5 } \\
N(\text { valid })=132, \\
N(\text { missing })=5\end{array}$ & $\begin{array}{l}\text { Q7 } \\
N(\text { valid })=131 \\
N \text { (missing) }=6\end{array}$ & $\begin{array}{l}\text { Q9 } \\
N \text { (valid) }=126, \\
N \text { (missing) }=11\end{array}$ \\
\hline Never & 39 (29.5\%) & 123 (94.6\%) & 114 (86.4\%) & 76 (58.0\%) & 74 (58.7\%) \\
\hline Little & 28 (21.2\%) & $2(1.5 \%)$ & 12 (9.1\%) & 21 (16\%) & $19(15.1 \%)$ \\
\hline Some & $5(3.8 \%)$ & $1(0.8 \%)$ & $0(0 \%)$ & $5(3.8 \%)$ & $5(4 \%)$ \\
\hline Occasionally & $43(32.6 \%)$ & $3(2.3 \%)$ & $4(3.0 \%)$ & $21(16 \%)$ & 25 (19.8\%) \\
\hline A great deal & 17 (12.9\%) & $1(0.8 \%)$ & $2(1.5 \%)$ & $8(6.1 \%)$ & $3(2.4 \%)$ \\
\hline Total $N$ & $132(100 \%)$ & $130(100 \%)$ & $132(100 \%)$ & $131(100 \%)$ & $126(100 \%)$ \\
\hline
\end{tabular}

Note: Frequencies are presented as $n$ (\%). Please refer to $\mathbf{- F i g . ~} 1$ for full question dialogue.

Table 2 Summary of Pearson r correlations for spinal patients' Internet use and pain catastrophizing subscales/total score

\begin{tabular}{|l|l|l|l|l|}
\hline Variables & Rumination & Magnification & Helplessness & PCS total \\
\hline Q1 $(n=132)$ & 0.134 & 0.089 & 0.169 & 0.152 \\
\hline Q3 $(n=130)$ & 0.113 & 0.088 & 0.139 & 0.129 \\
\hline Q5 $(n=132)$ & 0.048 & $0.210^{\text {a }}$ & 0.147 & 0.140 \\
\hline Q7 $(n=131)$ & 0.069 & 0.105 & 0.144 & 0.120 \\
\hline Q9 $(n=126)$ & 0.107 & 0.170 & 0.120 & 0.138 \\
\hline Q1+Q7 $(n=128)$ & 0.117 & 0.121 & $0.206^{\text {a }}$ & 0.171 \\
\hline Q3+Q5 $(n=130)$ & 0.102 & $0.203^{\text {a }}$ & $0.187^{\text {a }}$ & $0.177^{\text {a }}$ \\
\hline
\end{tabular}

Abbreviations: IUSP, Internet use and spine patients; PCS, pain catastrophizing scale.

Note: Pearson $r$ correlations for spinal patients' perceptions are presented above.

aCorrelation is significant at the 0.05 level (2-tailed). Q1+Q7 represents “Information' subscale of IUSP, Q3+Q5 represents "Support" subscale of IUSP. 
Internet use relates to pain catastrophizing. First, the findings of the demographics show that $4 \%$ of our sample-population does not utilize the Internet in any form (phone, tablet, computer, other). Additionally, the participants who did not use the Internet in any form had a higher overall mean age $(\mathrm{M}=73, \mathrm{SD}=8.426)$ compared with participants who did use the Internet $(M=52.17, S D=13.100)$. In regard to spinal patients' pain catastrophizing, scores were compared with a normed chronic pain population's score-to-percentile table developed by Sullivan. ${ }^{17}$ Our study shows that the mean pain catastrophizing scores (rumination, magnification, helplessness, and total) for our rural spine patient sample had overall higher pain catastrophizing on all subscales as compared with a chronic pain normed population.

Regarding spine patients' Internet use, questions addressed whether they were utilizing the Internet to gain information (Q1 and Q7) and/or support (Q3 and Q5) for their pain problem. Overall, results indicate that the Internet is being used primarily for information compared with support (-Table $\mathbf{1}$ ). Additionally, those who do use the Internet for information are finding the material from these Web sites to be somewhat helpful overall (Q2 and Q8). Conversely, very few spine patients utilize the Internet for support purposes. For those individuals who did use the Internet for support, most reported these Internet supports (i.e., social media and online support groups) were not at all helpful to them (Q4 and Q6). These findings support the initial hypothesis that rural spine patients will use the Internet primarily for information. This finding is supported through other literature, which suggests that rural patients' generally do not access psychological support services due to patient beliefs. ${ }^{19-21}$

The second hypothesis addressed the use of the Internet for support and elevated pain catastrophizing. Overall, the results of this study highlighted the relationship between catastrophizing and spine patients' Internet use. There was one positive correlation between PCS-subscale magnification and the use of social media for support purposes $(r=0.210 ; p<0.05)$ ( - Table 2). Additionally, when the subscales on the IUSP (information and support) were computed, there was a positively correlated relationship between Internet use for support and pain magnification, helplessness, and overall pain catastrophizing. The IUSP subscale, information, was also correlated with the PCS subscale helplessness, which may indicate that individuals who utilize the Internet are finding themselves feeling helplessness regarding their spinal pain.

There has been concern in the medical community about the utility of the Internet clinical practice. ${ }^{5-7}$ However, the current study indicates that Internet use for Information does not generally appear to be congruent with maladaptive coping in rural spinal surgery patients, but rather is used to potentially cope with helplessness after a spinal diagnosis. However, Internet use for support did positively correlate with overall catastrophizing, as well as PCS subscales magnification, helplessness.

There are several limitations to this study. The first limitation threatens the internal validity through the use of the IUSP measure that was developed specifically for this study. While this questionnaire asks about the use of the Internet for information and support, it has not been validated for its overall psychometric properties. A second limitation is the potential that this study cannot be generalizable to the population due to the location and rural Appalachia population. It is unknown how external and internal biases may have impacted the participants' responses on the questionnaires.

With these limitations in mind, several recommendations and future directions are provided. First, this study provides researchers and clinicians with insight into how spinal patients are using the Internet. While clinicians may have concerns about the Internet contributing to maladaptive coping, our data shows that participants are using the Internet mainly to gain more information. Furthermore, the patients who are utilizing the Internet for information are finding this information to be somewhat helpful.

It is recommended that clinicians provide clients with Web sites that are information-based, and rooted in evidenced-based practices and research. It is also recommended that clients who do utilize social media for support are receiving psychological help for possible difficulties with rumination related to their pain.

\section{Conclusion}

Clinicians are beginning to judge whether the Internet is a positive or negative strategy for gaining information or support for their patients' spinal conditions. This study provides a descriptive look at how spinal surgery patients are utilizing the Internet, as well as how the Internet is linked to pain catastrophizing. Results indicate that patients mainly use the Internet to gain information and are finding this tool to be somewhat helpful. Additionally, data shows that utilizing the Internet for support is positively correlated with overall pain catastrophizing, as well as PCS subscales magnification and helplessness. This finding may warrant additional research to examine the use of social media for support, and how this may significantly impact patients' views of their chronic pain conditions.

\section{Funding}

None.

\section{Conflict of Interest}

None declared.

\section{References}

1 Anderson M, Perrin A, Jiang J, Kumar M. 10\% of Americans don't use the internet. Who are they? Pew Research Center. Available at: https://www.pewresearch.org/facttank/2019/04/22/some-americans-dont-use-the-internetwho-are-they/. Accessed June 24, 2019

2 Eysenbach G, Kohlet Ch. What is the prevalence of health-related searches on the World Wide Web? Qualitative and quantitative analysis of search engine queries on the Internet. AMIA Annual Symposium Proceedings Archive. 2003:225-229

3 de Boer MJ, Versteegen GJ, van Wijhe M. Patients' use of the Internet for pain-related medical information. Patient Educ Couns 2007;68(1):86-97 
4 Baker JF, Devitt BM, Kiely PD, et al. Prevalence of Internet use amongst an elective spinal surgery outpatient population. Eur Spine J 2010;19(10):1776-1779

5 Murray E, Lo B, Pollack L, et al. The impact of health information on the Internet on health care and the physician-patient relationship: national U.S. survey among 1.050 U.S. physicians. J Med Internet Res 2003;5(3):e17

6 van Uden-Kraan CF, Drossaert CH, Taal E, Smit WM, Seydel ER, van de Laar MA. Experiences and attitudes of Dutch rheumatologists and oncologists with regard to their patients' health-related Internet use. Clin Rheumatol 2010;29(11):1229-1236

7 Tonsaker T, Bartlett G, Trpkov C. Health information on the Internet: gold mine or minefield? Can Fam Physician 2014;60(5):407-408

8 White RW, Horvitz E. Cyberchondria: studies of the escalation of medical concerns in web search. ACM Trans Inf Syst 2009;27(4):1-37

9 Iverson SA, Howard KB, Penney BK. Impact of internet use on health-related behaviors and the patient-physician relationship: a survey-based study and review. J Am Osteopath Assoc 2008;108(12):699-711

10 Lethem J, Slade PD, Troup JDG, Bentley G. Outline of a fear-avoidance model of exaggerated pain perception-I. Behav Res Ther 1983;21(4):401-408

11 Celestin J, Edwards RR, Jamison RN. Pretreatment psychosocial variables as predictors of outcomes following lumbar surgery and spinal cord stimulation: a systematic review and literature synthesis. Pain Med 2009;10(4):639-653

12 Wilhelm M, Reiman M, Goode A, et al. Psychological predictors of outcomes with lumbar spinal fusion: a systematic literature review. Physiother Res Int 2017;22(2):e1648
13 Gatchel RJ, Rollings KH. Evidence-informed management of chronic low back pain with cognitive behavioral therapy. Spine J 2008;8(1):40-44

14 Henderson EM, Keogh E, Rosser BA, Eccleston C. Searching the internet for help with pain: adolescent search, coping, and medication behaviour. Br J Health Psychol 2013;18(1):218-232

15 Gibler RC, Jastrowski Mano KE, O'Bryan EM, Beadel JR, McLeish AC. The role of pain catastrophizing in cyberchondria among emerging adults. Psychol Health Med 2019;24(10):1267-1276

16 Heppner PP, Wampold BE, Owen J, Thompson MN, Wang KT. Research Design in Counseling 4th edition. Boston, MA: Cengage Learning; 2016

17 Faul F, Erdfelder E, Buchner A, Lang A-G. Statistical power analyses using $G^{*}$ Power 3.1: tests for correlation and regression analyses. Behav Res Methods 2009;41(4):1149-1160

18 Sullivan MJL. The pain catastrophizing scale: development and validation. Psychol Assess 1995;7(4):524-532

19 Brenes GA, Danhauer SC, Lyles MF, Hogan PE, Miller ME. Barriers to mental health treatment in rural older adults. Am J Geriatr Psychiatry 2015;23(11):1172-1178

20 Solway E, Estes CL, Goldberg S, Berry J. Access barriers to mental health services for older adults from diverse populations: perspectives of leaders in mental health and aging. J Aging Soc Policy 2010;22(4):360-378

21 Deen TL, Bridges AJ, McGahan TC. Andrews AR III. Cognitive appraisals of specialty mental health services and their relation to mental health service utilization in the rural population. J Rural Health 2012;28(2):142-151 